\title{
Agro-industrial Orange Waste as a Low Cost Substrate for Carotenoids Production by Rhodotorula mucilagenosa
}

\author{
Omar, Sabrien A. and M.A.E. Selim
}

Microbiology Department, Faculty of Agriculture, Mansoura University, Egypt

Received on: $17 / 3 / 2019$

Accepted for publication on: 19/3/2019

\section{Abstract}

Carotenoids have many important biological activities, which can be used as food colorants and as a natural antioxidant pigments. A local yeast strain was isolated from karish cheese and identified as $R$. mucilagenosa. The efficiency of carotenoids production by $R$. mucilagenosa was tested by using orange waste extract (OWE) as an agro-industrial waste to minimize carotenoids production cost. To optimize the fermentation conditions, OWE medium was supplemented with different carbon and nitrogen sources at concentration $1 \%$ and $1-6 \% \mathrm{NaCl}$. The highest carotenoids production and cell dry weight $(7.2 \mathrm{mg} / 1$ and $13.75 \mathrm{~g} / \mathrm{l} \mathrm{re}-$ spectively) were obtained with OWE medium supplemented with $1 \%$ glucose, $1 \%$ yeast extract and $1 \% \mathrm{NaCl}$, at optimal $\mathrm{pH} 6$, temperature $25^{\circ} \mathrm{C}$ and shaking at $150 \mathrm{rpm}$ for five days.

Keywords: Carotenoids, Rhodotorula and Orange waste.

\section{Introduction}

Carotenoids are yellow to orange-red pigments, which widely distributed in nature. These pigments comprise around 700 different chemical structures. They can be found in algae, filamentous fungi, yeasts, bacteria and plants. However, animals are not able to synthesize carotenoids (Stafsnes et al., 2010).

Carotenoids have an important biological activity due to their provitamin A activity, antioxidant action by neutralizing free radicals as electron donor and anti-carcinogenic properties (Young and Lowe 2001).

There is increasing interest in naturally obtained carotenoids by biotechnological processes because of their growing demand in pharmaceutical, cosmetic, food, and feed industries, (Aksu and Eren 2005).

Microbial activities offer a promising method for carotenoids production (Johnson and Schroeder, 1995). Yeasts are better than algae or fungi for large scale production of carotenoids in fermenters, because of their unicellular nature and high growth rate (Baraka et al., 2014). Various genera of red yeasts, such as Cryptococcus, Rhodosporidium, Rhodotorula, Sporobolomyces and Xanthophyllomyces can produce and accumulate carotenoids in their cells (Hennekens 1997).

Among different yeasts, Rhodotorula sp. gave a favorable high yield producer of carotenoids (Frengova and Beshkova 2009). Rhodotorula has the ability to grow in various cheap agricultural raw materials such as sugar cane juice, peat extract, whey, grape must, beet molasses, and sugar cane molasses, so it is potentially useful for carotenoid production industry (Aksu and Eren 2005; Bhosale and Gadre 2001a; Buzzini and Martini 1999; Park et al., 2005 and Simova et al., 2004).

Citrus fruit is one of the commercial crops in the Egyptian mar- 
kets. About $50-60 \%$ of citrus fruit is transformed into waste by citrus processing industry (Wilkins et al., 2007). This results in accumulation of large quantities of citrus waste. This waste represents a major challenge in the citrus processing industries in Egypt and worldwide.

In this study, orange waste extract (OWE) was chosen as affordable and suitable substrate for carotenoids production by Rhodotorula with a view to reduce production costs and make the product economical.

Materials and Methods

Preparation of orange waste extract medium

Orange waste was collected from fruit juice shops at Mansoura City, Egypt. Orange waste extract (OWE) was prepared by adding two liters of distilled water to one kilogram of orange waste, boiled at 100 ${ }^{\circ} \mathrm{C}$ for 30 minutes, and then filtered to obtain orange waste extract. The OWE was used as fermentation medium to produce carotenoids using isolated yeast.

\section{Microorganisms}

An orange-pigmented yeast was isolated from yogurt and karish cheese samples. The yeast isolate was purified on GPY agar medium (yeast extract $10 \mathrm{~g}$, peptone $20 \mathrm{~g}$, glucose 20 $\mathrm{g}$, and one liter of distilled water). The purity of the obtained isolate was verified microscopically. Isolate was subcultured and maintained on GPY agar medium at $4^{\circ} \mathrm{C}$. The isolate was identified by Sigma Scientific Services Co., using 18s rRNA gene (Kanzy et al., (2015).

\section{Inoculum preparation}

Five $\mathrm{ml}$ of sterilized distilled water were added into $48 \mathrm{~h}$. yeast slant grown on GPY agar medium. The growth was scratched and homogenized well, then transferred into in $250 \mathrm{ml}$ Erlenmeyer flask contain $50 \mathrm{ml}$ of GPY broth medium. Flask was incubated for $24 \mathrm{~h}$. at $25^{\circ} \mathrm{C}$ with shaking at $150 \mathrm{rpm}$. inoculum contains $10^{6} \mathrm{CFU} / \mathrm{ml}$.

\section{Production of carotenoids on OWE medium}

Fifty $\mathrm{ml}$ of OWE medium was inoculated with one $\mathrm{ml}$ of the inoculum and incubated for 5 days at $25^{\circ} \mathrm{C}$ with shaking at $150 \mathrm{rpm}$. Yeasts cultures were centrifuged at 10000 for $20 \mathrm{~min}$. Yeast cells were collected for carotenoids determination.

\section{Optimization of carotenoids pro- duction}

Several factors including incubation period, carbon sources, nitrogen sources, salinity, inoculum size, initial $\mathrm{pH}$ value and temperature were optimized for carotenoids production using OWE liquid medium. Final $\mathrm{pH}$ values, cell dry weight (CDW) (g/l) and carotenoids production (mg / l) were determined.

\section{Effect of incubation period}

The selected isolate strain was cultivated in $250 \mathrm{ml}$ Erlenmeyer flask containing $50 \mathrm{ml}$ autoclaved OWE medium, the initial $\mathrm{pH}$ was 4.7, Each flask was inoculated with $1 \mathrm{ml}$ of inoculum and incubated at $25^{\circ} \mathrm{C}$, with shaking speed of $150 \mathrm{rpm}$. During incubation periods, samples were taken every $24 \mathrm{~h}$. for 10 successive days.

\section{Effect of additive carbon source}

To determine the best additive carbon source for carotenoids production, OWE medium were supplemented with $1 \%$ of different carbon sources; glucose, fructose, sucrose, maltose, mannitol, glycerol and 
starch. Flasks were inoculated with one $\mathrm{ml}$ of inoculum and incubated at $25^{\circ} \mathrm{C}$ with shaking at $150 \mathrm{rpm}$ for 5 and 6 days.

\section{Effect of different nitrogen Sources}

OWE medium, contained the best carbon source were supplemented with $1 \%$ of different nitrogen sources; yeast extract, beef extract, peptone, malt extract, ammonium phosphate, calcium nitrate and ammonium sulphate. Flasks were inoculated with one $\mathrm{ml}$ of inoculum and incubated at $25^{\circ} \mathrm{C}$ with shaking at $150 \mathrm{rpm}$ for 5 and 6 days.

\section{Effect of Initial pH}

To estimate the effect of $\mathrm{pH}$ value on carotenoids production by the yeast strain, OWE medium (contained best carbon and nitrogen source) was adjusted at $\mathrm{pH}$ values; 3 , $4,5,6,7$ and 8. Flasks were inoculated with one $\mathrm{ml}$ of inoculum and incubated at $25^{\circ} \mathrm{C}$ with shaking at $150 \mathrm{rpm}$ for 5 days.

\section{Effect of temperature}

OWE medium amended with best carbon and nitrogen source and adjusted at optimum $\mathrm{pH}$ was inoculated with one $\mathrm{ml}$ of inoculum and incubated at different temperatures; $22,25,28$ and $30 \square$ with shaking at $150 \mathrm{rpm}$ for 5 days.

\section{Effect of inoculum size}

Different inoculum sizes (2-10 $\%)$ were tested to estimate the effect of inoculum size on carotenoids production. OWE medium amended with best carbon and nitrogen source and adjusted at optimum $\mathrm{pH}$ were inoculated. Flasks were incubated at optimum temperature with shaking at 250 rpm for 5 days.

\section{Effect of salinity}

The effect of adding different concentrations of $\mathrm{NaCl}(1-6 \%)$ on yeast growth and carotenoids production was studied. Flaks were incubated under the optimum conditions for 5 days.

\section{Determination of total carotenoids}

According to the modified method of Park et al. (2005), $50 \mathrm{ml}$ of fermented broth culture was centrifuged at $5000 \mathrm{rpm}$ for $15 \mathrm{~min}$. The precipitate cells were washed twice by distilled water. After cells separation by centrifugation, $10 \mathrm{ml}$ of $0.1 \mathrm{~N}$ $\mathrm{HCl}$ were added, boiled in water bath for $15 \mathrm{~min}$., and then cooled in ice water for 10 minutes. For extraction of the pigments, the cells suspended in acetone and stirred vigorously until cells turn colorless, then equal amount of diethyl ether were added. This mixture was transferred in separating funnel. Cold $\mathrm{NaCl}$ solution $(15 \%)$ were added as a part of purification steps of the carotenoid pigment. To determine the total carotenoids, the diethyl ether layer was taken and assayed spectrophotometrically at $455 \mathrm{~nm}$. (JENWAY 6305 UV/vis. Spectrophotometer). The standard curve was blotted using $\beta$ carotene (MP Biomedicals, LLC) as a standard substrate. Amounts of carotenoids were calculated using standard curve.

\section{Determination of cells dry weight}

$50 \mathrm{ml}$ of yeast culture were centrifuged for $20 \mathrm{~min}$. at $10000 \mathrm{rpm}$, washed twice with distilled water and then dried at $80^{\circ} \mathrm{C}$ till constant weight. 


\section{Results and Discussion}

\section{Isolation and Identification of Rhodotorula mucilaginosa}

An orange-pigmented yeast isolate was isolated from Karish cheese. The yeast isolate gave an orange-red color on GPY agar medium. Pure culture of the isolated yeast was examined microscopically. Isolated yeast was oval, non-spore forming and non-pseudo-true- mycelium former.

The potential $R$. mucilaginosa isolate was further identified by PCR targeting the 18S rRNA gene, which confirmed its belonging to $R$. mucilaginosa, the size of PCR amplicon is 567-bp (Fig 1). The nucleotide sequence of a $567 \mathrm{bp}$ internal fragment of the 18S rRNA locus was investigated in $R$. mucilaginosa isolate. NCBI blast is applied to compare the DNA sequence of 18S rRNA of isolate to other reference strains. The results revealed the sequences of PCR amplicon is highly significant similarity with $R$. mucilagenosa L4 (Fig $2)$. These results are consistent with Kanzy et al., (2015) who carried out the isolation and molecular identification of $R$. mucilaginosa strain isolated from salted cheese whey.

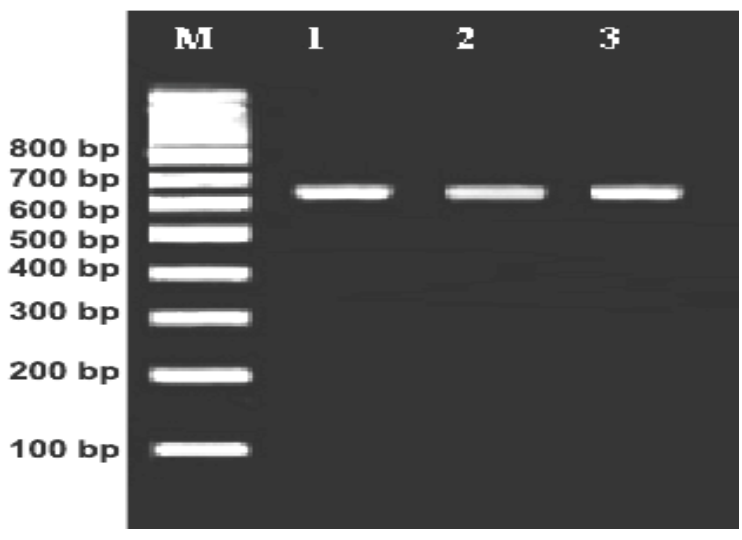

Fig. 1. Agarose gel electrophoresis (2\%) of PCR amplicon amplified with ITS primer pair. Lane M: $1 \mathrm{~kb}$ plus DNA ladder; Lane 1, 2 and 3 PCR products $18 \mathrm{~S}$ rRNA $R$. mucilagenosa.

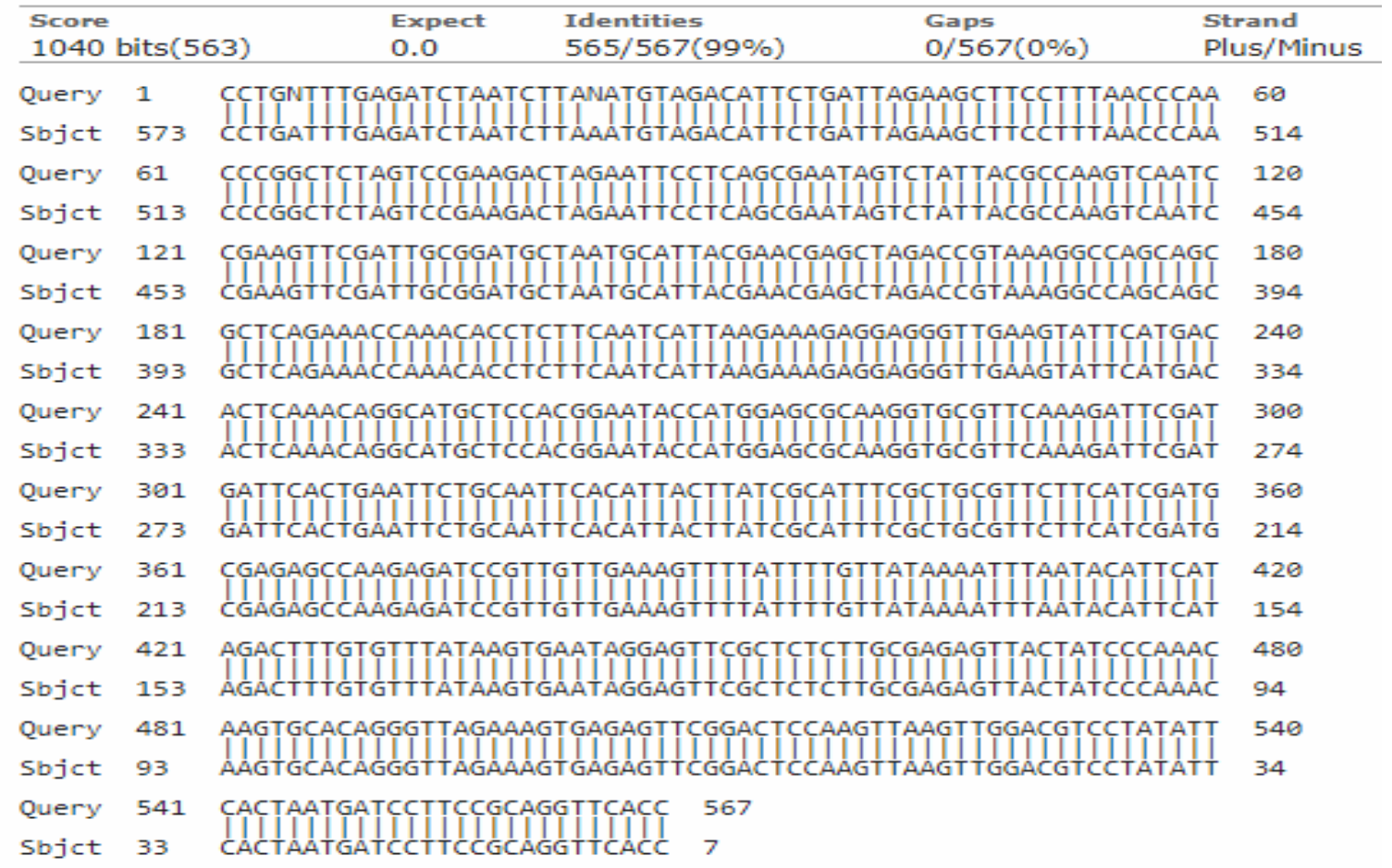

Fig 2: The degree of similarity between DNA sequences of 18rRNA gene of $R$. mucilagenosa to R. mucilagenosa L4 (reference strain), via NCBI blast. 


\section{Optimization of carotenoids pro- duction}

The biosynthesis of carotenoid is affected by many factors that can achieve the maximal carotenoid productivity and minimal operation cost. Therefore, the optimum conditions for growth and production of carotenoids have to be studied.

\section{Effect of incubation period}

Data presented in Fig 3. show the changes in cells dry weight (CDW) (g/l) and carotenoids production $(\mathrm{mg} / \mathrm{l})$ by $R$. mucilagenosa with time. During the first three days of incubation, $R$. mucilagenosa show exponential growth and decelerating growth until the sixth day then remained stationary, results also show that the production of carotenoids was growth correlated and directly related to the biomass yield. The maximum carotenoids production $(1.63 \mathrm{mg} / \mathrm{l})$ was achieved within seven days of incubation using OWE broth medium as a sole substrate while the maximum $\mathrm{CDW}$ was obtained after six days. Our results are in agreement with Bhosale and Gadre (2001b) who reported that, the carotenoids production in the yeast was growth associated. Also El Bana et al., (2012) stated that, the maximum yield of carotenoids achieved by $R$. glutinis at the fifth day. Korumilli and susmita (2014) who mentioned that maximum carotenoids production by Rhodotorula sp. was achieved at the end of logarithmic growth phase.

On the other hand, results are in contrast to those of Kanzy et al., (2015) who reported that, by using $R$. glutinis, the production of carotenoid started after the end of logarithmic growth phase then increased during stationary phase. Also (Marova et. al., 2012) reported that, maximum yield of carotenoids collected after 80 h. from R. glutinis.

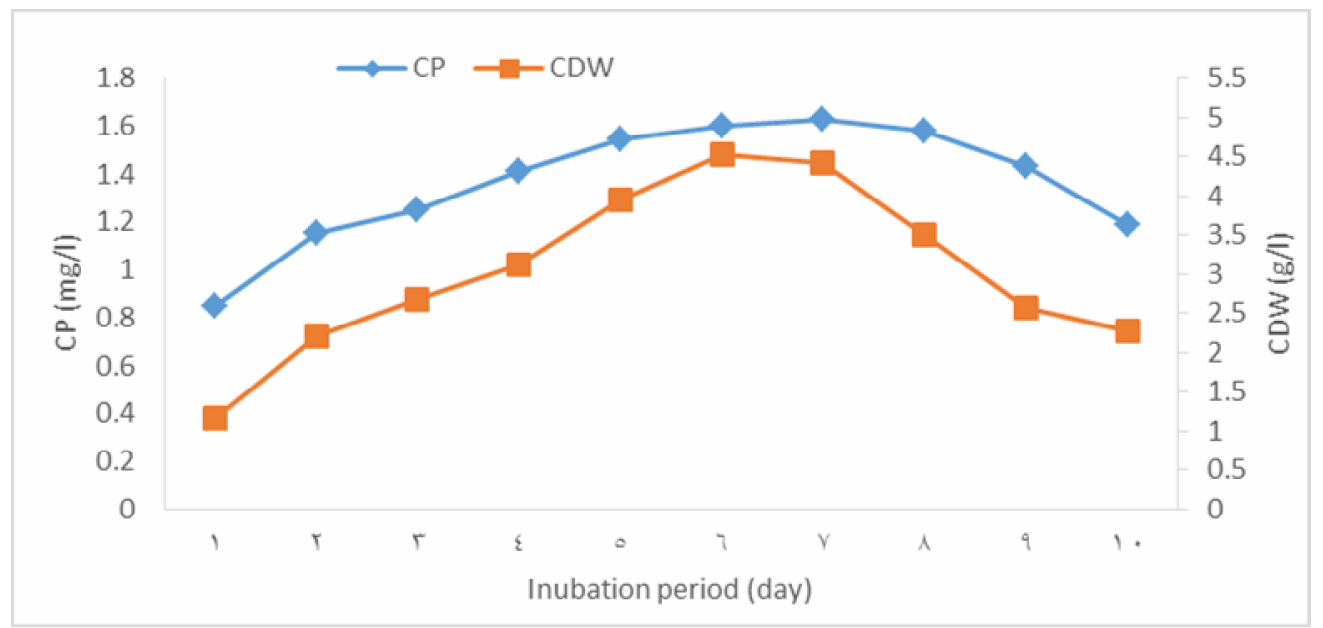

CP: Carotenoids production; CDW: Cells dry weight

Fig. 3: Effect of incubation period on growth (g/l) and carotenoids production (mg/l) by R. mucilagenosa

\section{Effect of different carbon sources}

Data in Fig. 4 illustrate the effect of different carbon sources on cells dry weight (CDW) and carotenoids production by $R$. mucilagenosa after five and six days of incubation 
at $25^{\circ} \mathrm{C}$. Data illustrate that maximum carotenoids production $(2.7 \mathrm{mg} / \mathrm{l})$ and CDW $(8.08 \mathrm{~g} / \mathrm{l})$ was observed with addition of $1 \%$ glucose to OWE medium after five days of incubation at $25{ }^{\circ} \mathrm{C}$, followed by mannitol. While, on the sixth day the best carbon source for carotenoids production was glucose $(2.8 \mathrm{mg} / \mathrm{l})$ followed by fructose and $(2.7 \mathrm{mg} / \mathrm{l})$, res, compared with $1.6 \mathrm{mg} / \mathrm{l}$ carotenoids and $3.5 \mathrm{~g} / \mathrm{l} \mathrm{CDW}$ which were obtained by control (OWE without carbon sources).

The results exhibit the correlation between the increasing the yeast biomass and carottenoids productiv- ity. Therefore, glucose at $1 \%$ concentration was selected as the best carbon source for further studies. These results were in line with Latha et al., (2005), they found that the highest pigmentation and growth by R.glutinis was achieved with glucose and fructose as carbon sources. Also, Baraka et al., (2014) stated that the best carbon sources for growth and carotenoids production by $R$. glutinis were glucose and sucrose. On the other hand, lactose was selected for Serratia marcescens to give the highest production of carotenoids (Wang et al., 2012).
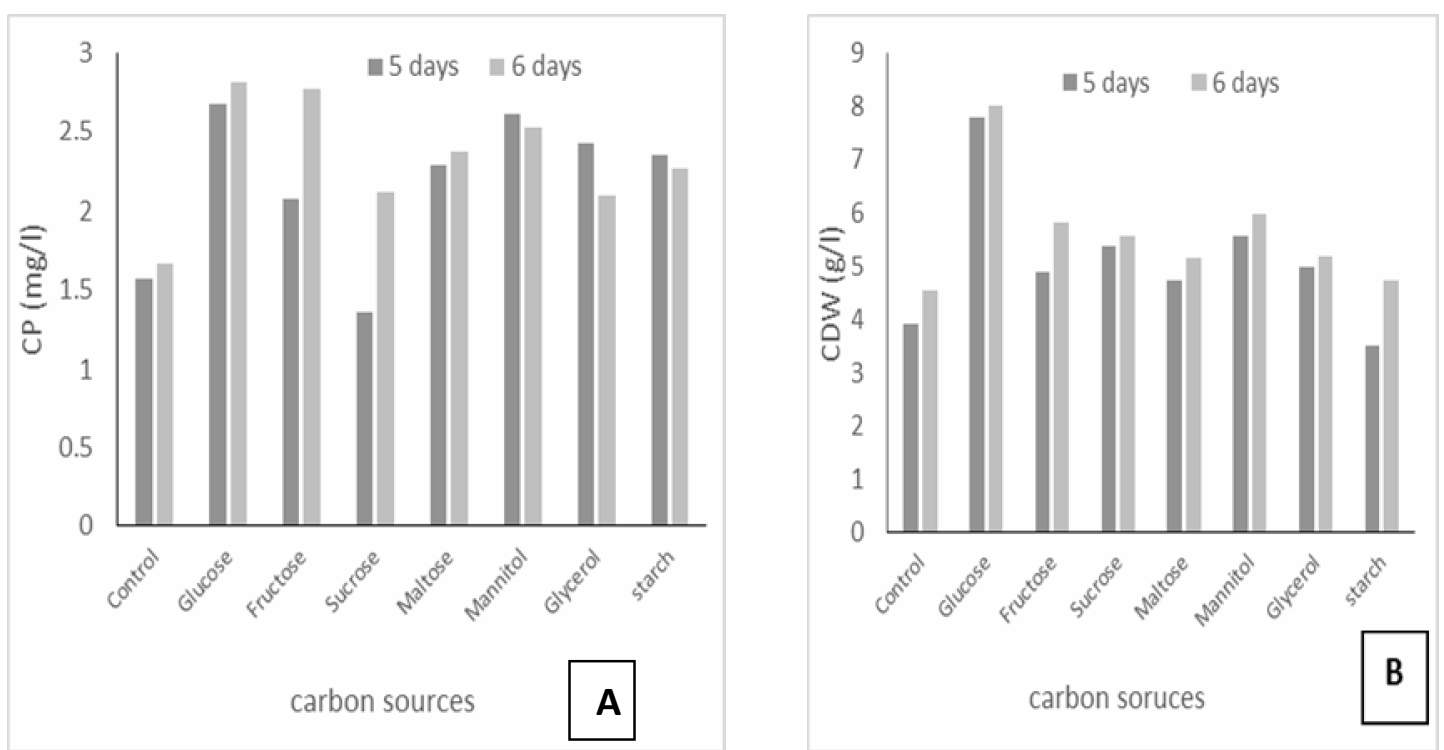

CP: Carotenoids production; CDW: Cells dry weight

Fig. 4. Effect of carbon sources on growth (g/l) (B) and carotenoids production (mg/l) (A) by R.mucilagenosa

\section{Effect of different nitrogen sources}

The influence of adding different nitrogen sources to the OWE medium amended with glucose on CDW and carotenoids production was investigated after four and five days of incubation at $25^{\circ} \mathrm{C}$. Data presented in Fig 5. revealed that the most tested nitrogen sources stimulated the growth and the carotenoids production by R.mucilagenosa compared with control (OWE amended with glucose without nitrogen sources). Also, the results show that yeast extract at $1 \%$ concentration was the best nitrogen source for carotenoids pro- 
duction $(5.7 \mathrm{mg} / \mathrm{l})$ and $\mathrm{CDW}(12.1$ $\mathrm{g} / \mathrm{l})$, followed by peptone $(4.3 \mathrm{mg} / \mathrm{l})$, ammonium sulphate $(3.8 \mathrm{mg} / \mathrm{l})$ and beef extract $(3.6 \mathrm{mg} / \mathrm{l})$ after five days of incubation. From the above results, it could be concluded that yeast extract is the best nitrogen source and so it is used in subsequent studies.

The results are in agreement with those obtained by Baraka et al.,

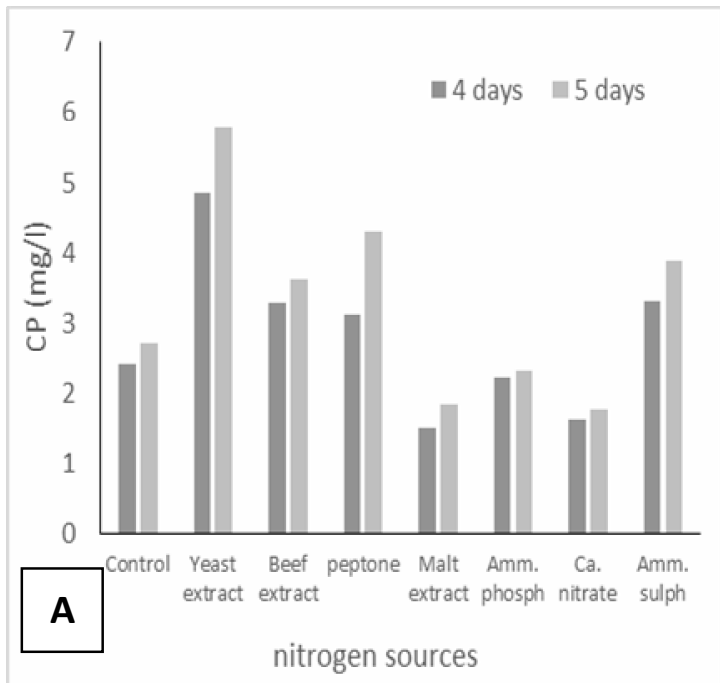

(2014) indicated that, yeast extract at a concentration of $0.75 \%$ was the best nitrogen source for carotenoid production and growth of $R$. glutinis. While Latha et al., (2005) demonstrated that, maximum carotenoids and growth of $R$. glutinis was observed with sodium nitrate as nitrogen source.

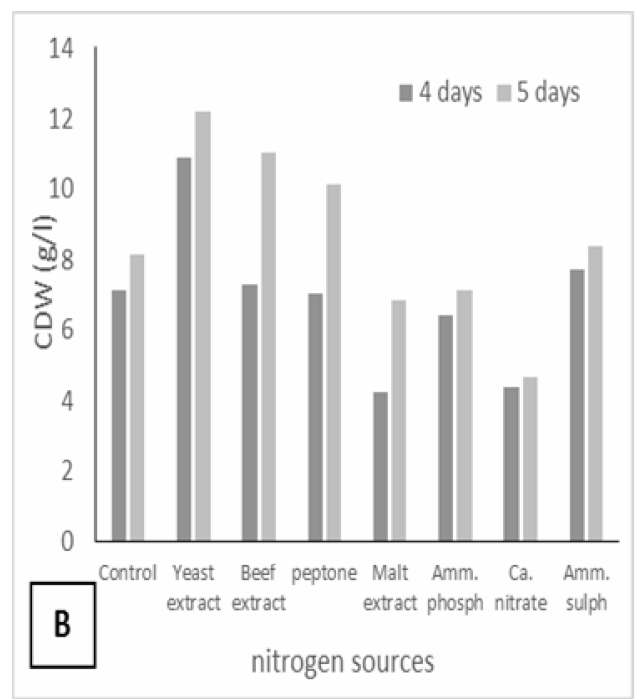

CP: Carotenoids production; CDW: Cells dry weight

Fig. 5. Effect of nitrogen sources on growth (g/l) (B) and carotenoids production (mg/l) (A) by R. mucilagenosa

\section{Effect of initial pH}

Fig. 6 shows the effect of initial $\mathrm{pH}$ values ranging from 3 to 8 on CDW and carotenoids production by $R$. mucilagenosa after 5 days of incubation at $25 \square$. The results show that $R$. mucilagenosa had ability to grow and produce carotenoids under a wide range of $\mathrm{pH}$. The highest carotenoids production $(5.98 \mathrm{mg} / \mathrm{l})$ and $\mathrm{CDW}$ $(12.5 \mathrm{~g} / \mathrm{l})$ were obtained at initial $\mathrm{pH}$ 6 . Therefore, $\mathrm{pH} 6$ could be consid- ered as the optimum $\mathrm{pH}$ for growth and carotenoids production by $R$. $m u-$ cilagenosa.

Similar results were obtained by Aksu and Eren (2007) and repeated that, $R$. glutinis produced maximum yield of carotenoids at $\mathrm{pH}$ 6. Also Kanzy et al., (2015) concluded that, the maximum level of carotenoids production achieved at $\mathrm{pH} 6.6$ for both $R$. glutinis and R. mucilagenosa. 


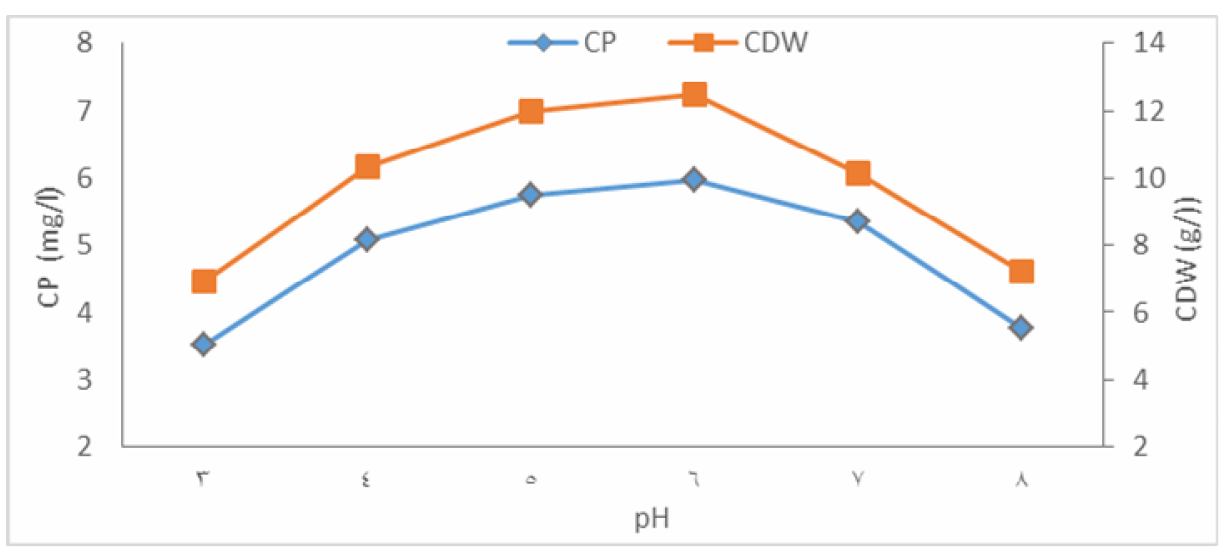

CP: Carotenoids production; CDW: Cells dry weight

Fig. 6. Effect of initial $\mathrm{pH}$ on growth (g/l) and carotenoids production (mg/l) by $R$. mucilagenosa

\section{Effect of temperature}

Temperature is another parameter, which affects the cell growing, and metabolites; it affects the biosynthetic pathways, including carotenogensis. Data presented in Fig. 7 show that $R$. mucilagenosa achieved highest carotenoids production $(5.98$ $\mathrm{mg} / \mathrm{l})$ and $\mathrm{CDW}(12.56 \mathrm{~g} / \mathrm{l})$ at $25^{\circ} \mathrm{C}$ after five days. Also the results show that carotenoids production and CDW decreased by decreasing temperature to $22{ }^{\circ} \mathrm{C}$ or increasing temperature to $28^{\circ} \mathrm{C}$.

Similar results were observed by El-Banna et al., (2012) who stated that, the optimal temperature for ca- rotenoids production and growth by $R$. glutinis was $25^{\circ} \mathrm{C}$. Also, Martin et al., (1993) Reported that, the optimum temperature was $22^{\circ} \mathrm{C}$ for $R$. rubra. On the other hand, Latha et al., (2005) Recorded that, the maximum carotenoid yield by $R$. glutinis DFRPDY was obtained at the ambient temperature $29-32^{\circ} \mathrm{C}$. Also, (Aksu and Eren 2005) reported that, $30^{\circ} \mathrm{C}$ was the optimum for $R$. mucilagenosa. It could be noticed that the effect of temperature on biosynthesis of carotenoid depends on the species specificity and strain characteristics.

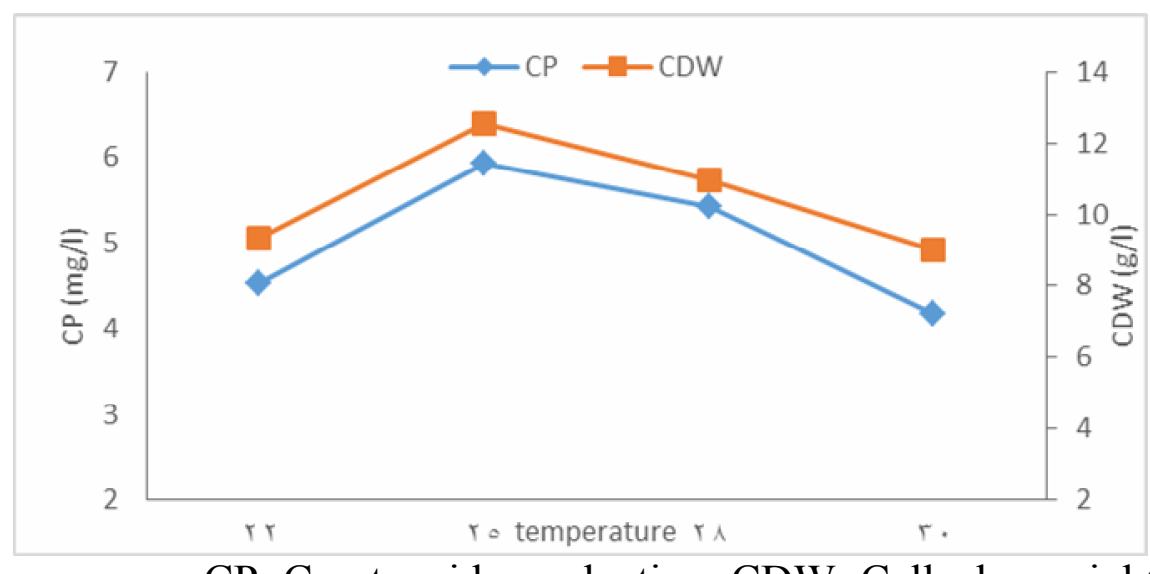

CP: Carotenoids production; CDW: Cells dry weight

Fig. 7. Effect of temperature on growth $(\mathrm{g} / \mathrm{l})$ and carotenoids production $(\mathrm{mg} / \mathrm{l})$ by $R$. mucilagenosa 


\section{Effect of inoculum size}

Fig 8. shows CDW and carotenoids production by R.mucilagenosa after five days of incubation with different inoculum sizes $(2,4,6,8$ and $10 \%(\mathrm{v} / \mathrm{v}))$. The results indicate that yeast growth and carotenoids production increased by increasing the inoculum size to $4 \%$, it is due to the direct relation between carotenoids production and yeast growth. With $4 \%(\mathrm{v} / \mathrm{v})$ of inculum size, $R$. mucilagenosa reached the maximum carotenoids production $(6.997 \mathrm{mg} / \mathrm{l})$ and CDW (13.61 g/l). By increasing the inoculum size to $6 \%$, a slight de- crease occurred in yeast growth and carotenoids production. Data also show that at higher ratios of inoculum sizes ( 8 and $10 \%)$, growth and carotenoids production decreased. That would be caused by the inhibition effect of metabolites products in culture medium which increased by increasing biomass. Bhat and Marar (2015) found that, maximum pigment production by Salinicoccus sp. was achieved with $2 \%$ inoculum. Also, Ji et al., (2012) obtained maximum yield of pigment with $2 \%$ inoculum by Monascus purpureus.

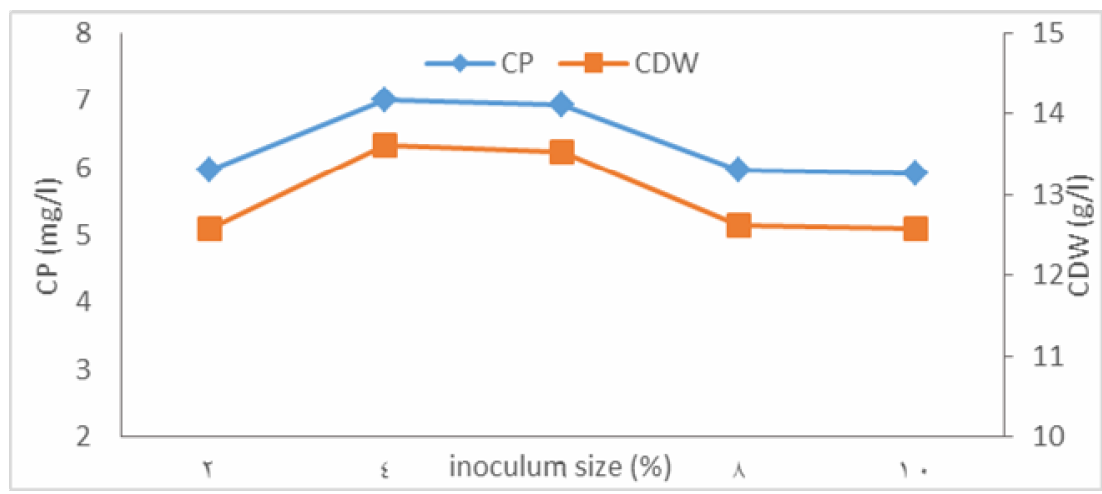

CP: Carotenoids production; CDW: Cells dry weight

Fig. 8. Effect of inoculum size on carotenoids production $(\mathrm{mg} / \mathrm{l})$ and yeast growth $(\mathrm{g} / \mathrm{l})$ by $R$. mucilagenosa

\section{Effect of salinity on carotenoids production and yeast growth}

The effect of salinity on CDW and carotenoids production by $R$. $m u$ cilagenosa was investigated in salted OWE medium (1-6 \% NaCl) after five days at $25^{\circ} \mathrm{C}$. The results in Fig. 9 showed that maximum carotenoids production $(7.2 \mathrm{mg} / \mathrm{l})$ and $\mathrm{CDW}$ $(13.72 \mathrm{~g} / \mathrm{l})$ were obtained at $1 \% \mathrm{NaCl}$ and by increasing the concentration of $\mathrm{NaCl}$, growth weight and carotenoids production decreased. Therefore, the obtained results demonstrate that this strain of yeast failed to pro- duce carotenoids at high concentration of $\mathrm{NaCl}$. Mahmoud et al., (2014) reported similar results, which stated that there was a high significant decrease in carotenoids production by Rhodotorula sp. with increasing concentrations of $\mathrm{NaCl}$. Also, they recorded that Rhodotorula sp. achieved highest values of carotenoids production with $2 \%$ of $\mathrm{NaCl}$.

On contrast with our results, Kanzy et al., (2015) reported that the maximum carotenoid production was achieved at $6 \% \mathrm{NaCl}$ by yeast strains of Rhodotorula. 


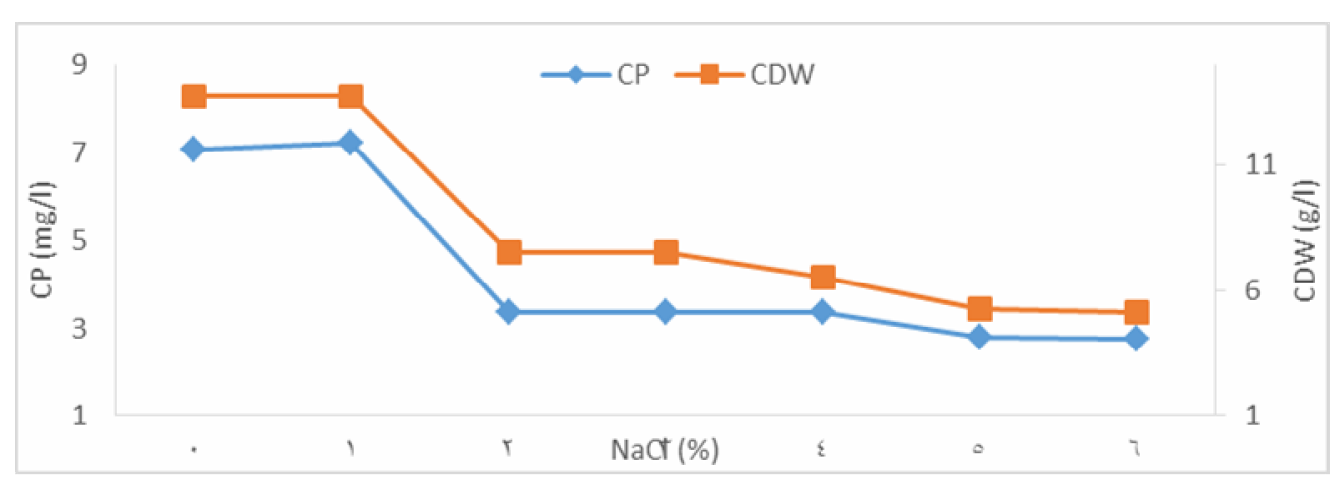

CP: Carotenoids production; CDW: Cells dry weight

Fig. 9. Effect of salinity on yeast growth $(\mathrm{g} / \mathrm{l})$ and carotenoids production $(\mathrm{mg} / \mathrm{l})$ by R. mucilagenosa

\section{Conclusion}

In the current study, the abundantly available and non-efficiently utilized orange waste was used as a substrate for low cost production of carotenoids by $R$. mucilagenosa isolated from karish cheese. The highest carotenoids production and yeast cells dry weight was obtained after 5 days at $25{ }^{\circ} \mathrm{C}$ with initial $\mathrm{pH} 6$ by adding $1 \%$ glucose, $1 \%$ yeast extract and $1 \% \mathrm{NaCl}$ to orange waste extract. The maximal carotenoids production was $7.2 \mathrm{mg} / \mathrm{l}$.

\section{References}

Aksu Z., Eren A.T. 2005. Carotenoids production by the yeast Rhodotorula mucilaginosa: Use of agricultural wastes as a carbon source. Process Biochem., 40: 2985-2991.

Aksu, Z. and Eren, A. T. 2007. Production of carotenoid by isolated of Rhodotorula glutinis. Biochem. Engin., 35:107-113.

Baraka A.A., Abeer E. A., Mohamed E.A. 2014. Using whey for Production of Carotenoids by Rhodotorula glutinis. Middle East J. Appl. Sci., 4(2): 385391.
Bhat M.R., Marar T. 2015. Media Optimization, Extraction and Partial Characterization of an Orange Pigment from Salinicoccus sp. MKJ 997975, Int. J. Life Sci. Biotech. Pharm. Res., 4 (2): 85-89.

Bhosale, P.، Gadre R.V. 2001a. $\beta$ Carotene production in sugar cane molasses by a Rhodotorula glutinis mutant. J. Ind. Microbiol. Biotechnol., 26: 327-332.

Bhosale P., Gadre R., 2001b. Optimization of Carotenoid Production from Hyper $\square$ Producing Rhodotorula glutinis Mutant 32 by a Factorial Approach, Lett in Appl. Microbiol., 33 (1):12-16.

Buzzini P., Martin A., 1999. Production of carotenoids by strains of Rhodotorula glutinis cultured in raw materials of agro industrial origin. Biores Technol., 71: 41-44.

El-Banna A.A., Amal A.M., Ahmed E.R. 2012. Some Factors Affecting the Production of Carotenoids by Rhodotorula glutinis var. glutinis. Food and Nutri. Sci., 3: 64-71.

Frengova G.I., Beshkova D.M. 2009. Carotenoids from Rhodotorula 
and Phaffia: Yeasts of Biotechnological Importance, J. of Industrial Microbiol. Biotechnol., 36 (2):163-180.

Hennekens C.H. 1997. $\beta$-Carotene Supplementation and Cancer Prevention, Nutrition, 13:697699.

Ji H., Jiang D., Cao L. 2012. Optimization of fermentation parameters on T-DNA inserted Monascus pyrpureus mutant MT24 with high pigment production capacity, Res. J. Biotechnol., 7: 9-14.

Johnson E. A., Schroeder W. A.1995. Microbial Carote-noids In: A. Fiecher, Ed., Advances Biochem. Eng. Biotechnol., 53: 119-178.

Kanzy M. H., Nasr N.F., Hoida A.M., Olfat S.B. 2015. Original Research Article Optimization of Carotenoids production by yeast strains of Rhodotorula using salted cheese whey, Int. J. Curr.Microbiol. App. Sci., 4(1): 456-469.

Korumilli T., Susmita M., 2014. Carotenoid Production by Rhodotorula sp. on Fruit Waste Extract as a Sole Carbon Source and Optimization of Key Parameters, Iran. J. Chem. Eng., 33(3):89-99.

Latha B.V., Jeevaratnam K., Murali H.S., Manja K.S. 2005. Influence of growth factors on carotenoids pigmentation of Rhodotorula glutinisDFR-PDY from natural source. Indian J. Biotechnol., 4: 353-357.

Mahmoud A.G., Atef M., Moustafa M., Wlaa T. 2014. The role of some stress factors including hydrogen peroxide, methylen blue, sodium chloride and ultraviolet on Rhodotorula glutinis DBVPG \# 4400 total carotenoids production, In. J. Biosci., 4 (9):10-19.

Marova,I; Carnecka, M; Halienova, A; Certik, M; Dvorakova, T and Haronikova. A. 2012. Use of several waste substrates for carotenoid-rich yeast biomass production. J. of Environ. Manag., 95:338-342.

Martin A., Lu C., Patel T. 1993. Growth parameters for the yeast Rhodotorula rubra grown in peat extract. J. Ferm. Bioeng, 76: 321-325.

Park P.K., Cho D.H., Kim E.Y., Chu K.H. 2005. Optimization of carotenoid production by Rhodotorula glutinis using statistical experimental design, World J. Microbiol. Biotechnol., 21: 429-434.

Simova E.D., Frengova G.I., Beshkova D.M. 2004. Synthesis of carotenoids by Rhodotorula rubra GED8 co-cultured with yogurt starter cultures in whey ultrafiltrate. J Ind Microbiol Biotechnol., 31: 115-121.

Stafsnes M.H., Josefsen K.D., Andersen G.K., Valla S., Ellingsen T.E., Bruheim P. 2010. Isolation and characterization of marine pigmented bacteria from norwegian coastal waters and screening for carotenoids with UVAblue light absorbing properties, J. Microbiol. 48(1):16-23.

Wilkins M.R., Suryawati L., Maness N.O., Chrz D. 2007. Ethanol production by Saccharomyces cerevisiae and Kluyveromyces 
marxianus in the presence of orange-peel oil. World J Microbiol Biotechnol.; 23(8):11611168.

Wang B., Lin L., Lu L., Chen W. 2012. Optimization of $\beta$ carotene production by a newly isolated Serratia marcescens strain, Elect. J. Biotechnol., 15 (6): 1-12.

Young, A. J., Lowe G. M. 2001. Antioxidant and prooxidant properties of carotenoids. Archives of Biochem. and Biophysics, 385: 20-27. 
استخدام مخلف عصر البرتقال كمادة خام رخيصة لإنتاج الكاروتينات بواسطة عزلية

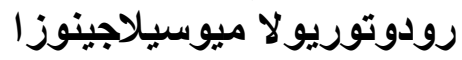

صابرين أحمد عمر ومحمد عبد الله العوضي سليم

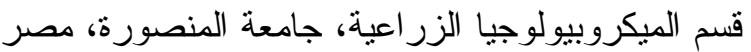

(الملخص

تعد الكاروتينات مركبات ذات أهمية كبيرة في الأنشطة البيولوجية، حيث يمكن استخدامها

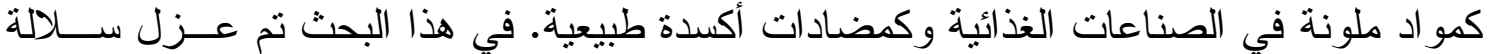

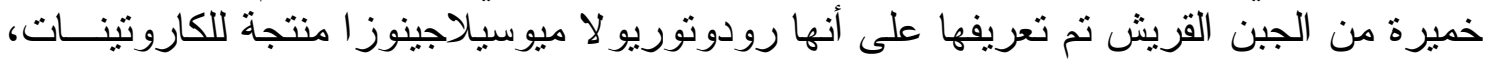
حيث تم استخدام مستخلص من مخلفات عصر البرتقال كمادة خام لإنتاج الكاروتينات من ســاتلالة

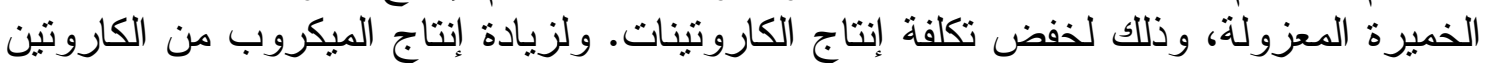

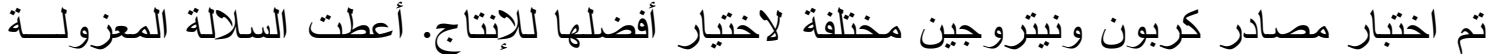

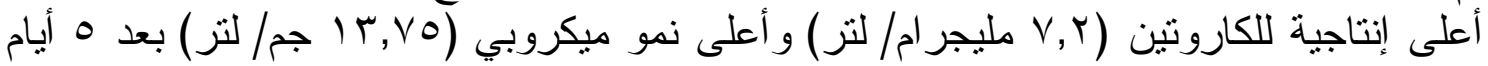

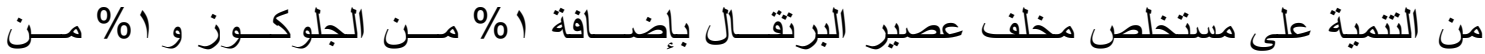

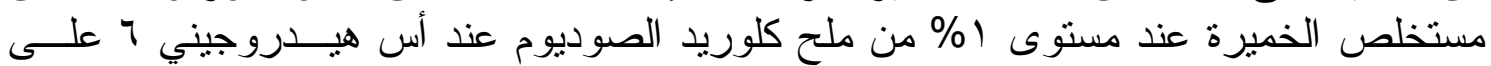

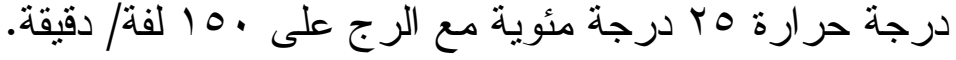

